\title{
Gas Deliverability Model with Different Vertical Wells Properties
}

\author{
L. Mucharam ${ }^{1}$, P. Sukarno ${ }^{1}$, S. Siregar ${ }^{1,3}$, Z. Syihab ${ }^{1}$, E. Soewono ${ }^{2,3}$, \\ M. Apri ${ }^{3} \&$ F. Irzal ${ }^{3}$ \\ ${ }^{1}$ Department of Petroleum Engineering ITB \\ ${ }^{2}$ Department of Mathematics ITB \\ ${ }^{3}$ Research Group for Industrial \& Applied Mathematics, - ITB
}

\begin{abstract}
We present here a gas deliverability computational model for single reservoir with multi wells. The questions of how long the gas delivery can be sustained and how to estimate the plateau time are discussed here. In order to answer such a question, in this case, a coupling method which consists of material balance method and gas flow equation method is developed by assuming no water influx in the reservoir. Given the rate and the minimum pressure of gas at the processing plant, the gas pressure at the wellhead and at the bottom hole can be obtained. From here, the estimation of the gas deliverability can be done. In this paper we obtain a computational method which gives direct computation for pressure drop from the processing plant to the wells, taking into account different well behavior. Here AOF technique is used for obtaining gas rate in each well. Further Tian \& Adewumi correlation is applied for pressure drop model along vertical and horizontal pipes and Runge-Kutta method is chosen to compute the well head and bottom hole pressures in each well which then being used to estimate the plateau times. We obtain here direct computational scheme of gas deliverability from reservoir to processing plant for single reservoir with multi-wells properties. Computational results give different profiles (i.e. gas rate, plateau and production time, etc) for each well. Further by selecting proper flow rate reduction, the flow distribution after plateau time to sustain the delivery is computed for each well.
\end{abstract}

Keywords: Absolute Open Flow (AOF); gas deliverability; production plateau.

\section{$1 \quad$ Introduction}

Computation of gas deliverability is an interesting and complicated problem in gas industries since it contains the question of how long a well(s) can still deliver gas to the sales point. With this calculation, the plateau time of the deliverability can be predicted which is in turn, if the gas delivery has reached that point while the contract time has not yet finished, then there are options to sustain the gas delivery by installing compressors or establishing a new well(s).

Several papers have shown computation for gas deliverability for single well properties (see for example in Fevang \& Whitson (1995) and Mott (1999)). In 
this paper, we present direct computation for deliverability from reservoir to the processing plant with multi wells properties. Here, gas rate and pressure at the processing plant are considered as the constraint of the calculation. This is used as a simplification of the problem. Provided a number of data, we can find out the pressure at the wellhead and at the bottom hole of each well. After computing the gas pressure at the bottom hole, the calculation of the gas deliverability can be started. However, it should be noticed that a gas well can only deliver certain percentage rate from its Absolute Open Flow (AOF). This will determine whether the gas rate from existing well(s) can meet the customer need.

The method of Runge-Kutta in solving the Tian \& Adewumi [3] correlation can be found in section 2 . In section 3 , we discuss about gas rate allocation that can be taken from each well, while AOF and material balance are talked in the next sections. Calculation results of deliverability and numerical analysis \& further discussion are presented in section 6 and 7 respectively.

\section{Gas Deliverability in a Vertical Well}

Gas delivery from a reservoir to the bottom hole and then to the processing plant and to the sales point will experience some pressure drop. Although the computation of the pressure distribution along these different pipelines should necessarily be calculated, we prefer to simplify the problem for the delivery up to the processing plant. Further calculation extending up to the sales point can be done similarly. In order to deliver gas from the bottom hole to the processing plant satisfying a given outlet pressure, the minimum pressure at the bottom hole $\left(\mathrm{P}_{\mathrm{wflimit}}\right)$ must be computed first using an appropriate pressure drop equation.

Basically, there are many equations available to estimate pressure drop of dry gas. The most popular equations for gas flow in horizontal and slightly inclined pipelines are Weymouth and Panhandle (A and B) equations. For bottom hole pressure calculation, Cullender-Smith and Sukkar-Cornel methods [4] can be applied. However, all of these equations do not include the kinetic energy term in it.

Recently, Tian \& Adewumi [3] developed an analytical equation for gas pipelines, which was derived from compressible fluid flow model in pipes without neglecting the kinetic energy term. This equation can be applied to predict the bottom-hole pressure for gas wells and also for pressure distribution in long pipes. This is being used here and can be described as follows 


$$
\frac{\dot{m} Z R T}{M_{g} A^{2} P^{2}} \frac{d P}{d x}=\frac{d P}{d x}+\frac{\dot{f m}^{2} Z R T}{2 D M_{g} A^{2} P}+\frac{M_{g} P \sin \alpha}{Z R T} .
$$

Rearranging (1), we get

$$
\frac{d P}{d x}=\frac{\frac{f \dot{m}^{2} Z R T}{2 D M_{g} A^{2} P}+\frac{M_{g} P \sin \alpha}{Z R T}}{\frac{\dot{m} Z R T}{M_{g} A^{2} P^{2}}-1} .
$$

Further by integrating (2) and assuming constant temperature and compressibility factor taken from the average values we obtain

$$
\left(\frac{Z R T}{2 M_{g} g \sin \alpha}+\frac{D}{f}\right) \ln \left(\frac{\frac{f \dot{m}^{2}}{2 D A^{2}}+\frac{M_{g}^{2} g P_{2}^{2} \sin \alpha}{Z^{2} R^{2} T^{2}}}{\frac{f \dot{m}}{2 D A^{2}}+\frac{M_{g}^{2} g P_{1}^{2} \sin \alpha}{Z^{2} R^{2} T^{2}}}\right)-\frac{D}{f} \ln \left(\frac{P_{2}^{2}}{P_{1}^{2}}\right)+L=0 .
$$

To obtain the desired pressure, the Newton-Raphson method is used. Another similar approach in [5] with different technique of averaging can also be used to derive a pressure drop equation. This averaging technique to integrate the pressure drop equation (2) is naturally far from accurate for relatively long pipe.

Here in this paper we use the full equation (2) for pressure drop calculation, precisely the fourth order Runge-Kutta method that is known with higher order accuracy is used for numerical computation. The local truncation error of this method is of order $\boldsymbol{O}\left(\mathbf{h}^{5}\right)$ and its global error is of order $\boldsymbol{O}\left(\mathbf{h}^{4}\right)$ [6]. This method is described below.

\subsection{Runge-Kutta Method}

Consider equation (2) as an initial value problem. To apply the Runge-Kutta method, we need all properties on the right side of the equation at starting point.

In short, the method can be described below

$$
P_{n+1}=P_{n}+\frac{1}{6}\left(K_{1}+2 K_{2}+2 K_{3}+K_{4}\right),
$$

with 


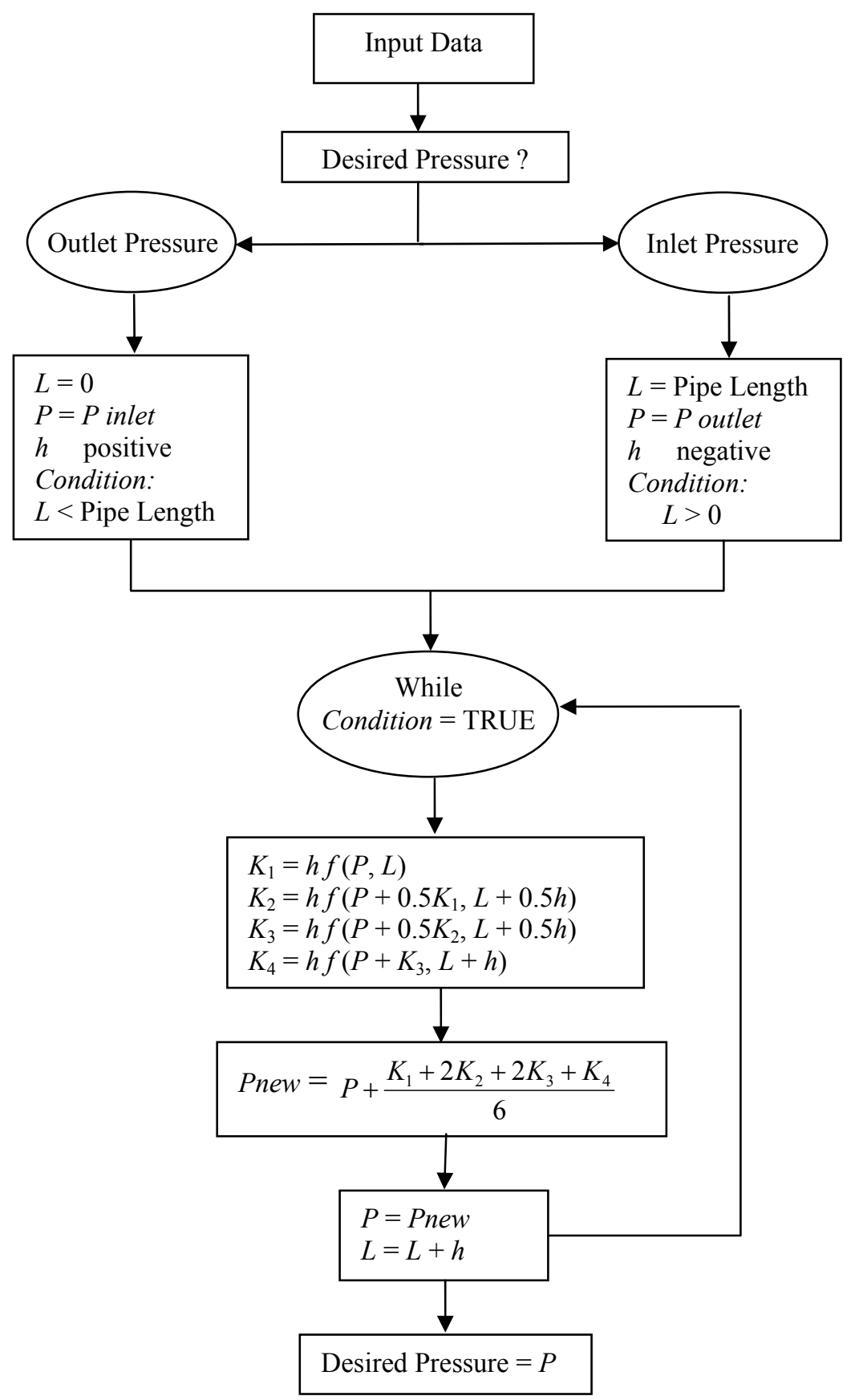

Figure 1 Runge-Kutta procedure in determining desired pressure. 


$$
\begin{aligned}
& K_{1}=h f\left(L_{n}, P_{n}\right) \\
& K_{2}=h f\left(L_{n}+\frac{h}{2}, P_{n}+\frac{K_{1}}{2}\right) \\
& K_{3}=h f\left(L_{n}+\frac{h}{2}, P_{n}+\frac{K_{2}}{2}\right) \\
& K_{4}=h f\left(L_{n}+h, P_{n}+K_{3}\right) .
\end{aligned}
$$

Take equation (2) as the $f(L, P)$ function. If we would like to estimate the inlet pressure, then $h$ must be a negative value and $L$ must be equal to the length of pipe. On the other hand, if the desired pressure is the outlet, then $h$ must be a positive value, and $L$ must be set equal to 0 .

As an illustration of the Runge-Kutta method, see the flow chart on figure 1.

\section{$3 \quad$ Rate Allocation}

Before going on to the deliverability calculation, it should be assured first that gas rate taken from the reservoir can satisfy the customer needs through the wells. This is because a gas well can only deliver certain percentage of its Absolute Open Flow (AOF). However, in this paper the value of AOF during the production time is estimated from the initial value of AOF. To determine gas rate distribution from each well, a weighted AOF calculation is used as depicted in figure 2 .

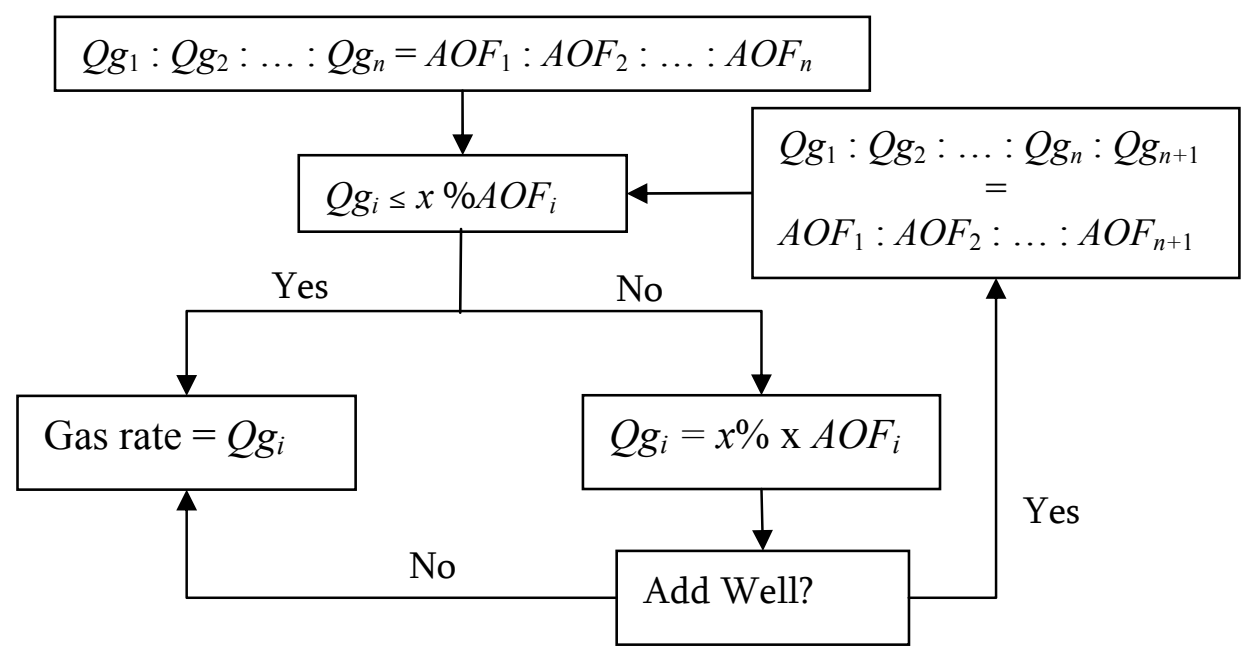

Figure 2 Determining gas rate from each well. 
Shortly, to calculate the deliverability, we can use the following equation [4]

$$
Q_{g}=C\left(P_{r}^{2}-P_{w f}^{2}\right)^{n} \text {. }
$$

\section{$4 \quad$ Absolute Open Flow (AOF)}

Absolute Open Flow is gas flow rate that could be obtained if the bottom hole pressure reduced to zero psig. Thus, the value of AOF can be written as follows

$$
A O F=C\left(P_{r}^{2}-14.73^{2}\right)^{n},
$$

where $\mathrm{C}$ can be written as follows

$$
C=0.703 \times 10^{-6} \frac{k h}{T \bar{\mu}_{g} \overline{\mathrm{z}} \ln \left(0.472 \frac{r_{e}}{r_{w}}\right)} .
$$

Since pressure of reservoir and the value of $\mathrm{C}$ change with the times, the AOF will also change with the production times. Hence, we could consider it as a function which depends on reservoir pressure and time. The estimation of AOF is very important here, because it will determine gas rate that can be produced from a well. However, it should be noticed that the value of AOF may be different for each well.

\section{$5 \quad$ Material Balance}

In calculating deliverability, we modify material balance method to estimate time production of reservoir. It is shown here a computation of production time which is derived from the material balance equation. For gas volumetric reservoir, the material balance can be represented as follows

$$
n_{p}=n_{i}-n_{f},
$$

where

$$
\begin{array}{ll}
n_{p} & =\text { amount of gas mole produced } \\
n_{i} & =\text { amount of initial gas mole at reservoir } \\
n_{f} & =\text { remained gas mole at reservoir. }
\end{array}
$$

By substituting real gas equation into equation (8), we will have

$$
\frac{p_{s c} G_{p}}{z_{s c} T_{s c}}=\frac{p_{i} V_{i}}{z_{i} T_{f}}-\frac{p V_{i}}{z T_{f}}
$$


and finally we get

$$
G_{p}=\left(-\frac{T_{s c} V_{i}}{p_{s c} T_{f}}\right) p / z+\left(\frac{T_{s c}}{p_{s c}}\right)\left(\frac{p_{i} V_{i}}{z_{i} T_{f}}\right)
$$

Because $V_{i}=\operatorname{IGIP} \times B g_{i}$ and $B g_{i}=0.0283 \frac{z_{i} T_{f}}{p_{i}} f^{3} / s c f$ then equation (10) can be simplified into

$$
G_{p}=\left(-\frac{I G I P}{p_{i} / z_{i}}\right) p / z+I G I P,
$$

where IGIP stands for Initial Gas In Place in scf unit.

Supposed that initial pressure, deviation factor, and IGIP (Initial Gas In Place) are already known. Because time ( $\mathrm{t}$ ) can be obtained from dividing $\mathrm{G}_{\mathrm{p}}$ by constant $Q_{g}$, then we can derive recursively function of time depend on $p / z$ as follows

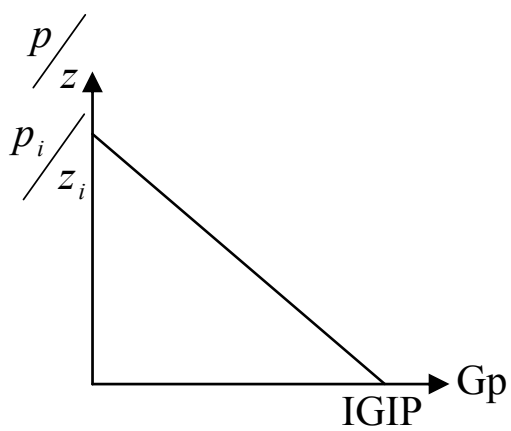

Figure 3.a Illustration of $P$ over $z$ vs IGIP.

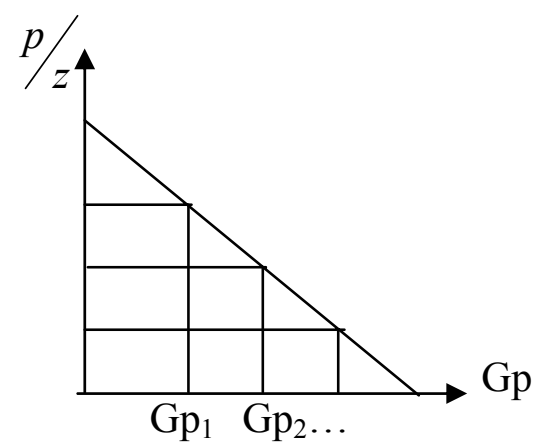

Figure 3.b Illustration of $P$ over $z$ vs Gp.

$$
t_{1}=\frac{G p_{1}}{Q_{g}}=\left(-\frac{I G I P}{Q_{g} p_{i} / z_{i}}\right) p_{1} / z_{1}+\frac{I G I P}{Q_{g}}
$$




$$
\begin{aligned}
& t_{2}=\frac{G p_{2}-G p_{1}}{Q_{g}}=-\frac{I G I P}{Q_{g} p_{i} / z_{i}}\left(p_{2} / z_{2}-p_{1} / z_{1}\right) \\
& t_{3}=\frac{G p_{3}-G p_{2}}{Q_{g}}=-\frac{I G I P}{Q_{g} p_{i} / z_{i}}\left(p_{3} / z_{3}-p_{2} / z_{2}\right)
\end{aligned}
$$

And finally we get function of time $(t)$, which depends on only pressure variable as follows:

$$
t_{n}=\frac{G p_{n}-G p_{n-1}}{Q_{g}}=-\frac{I G I P}{Q_{g} p_{i} / z_{i}}\left(p_{n} / z_{n}-p_{n-1} / z_{n-1}\right)
$$

An integrated calculation of flow performance from the reservoir to the processing plant is shown in figure 4 .

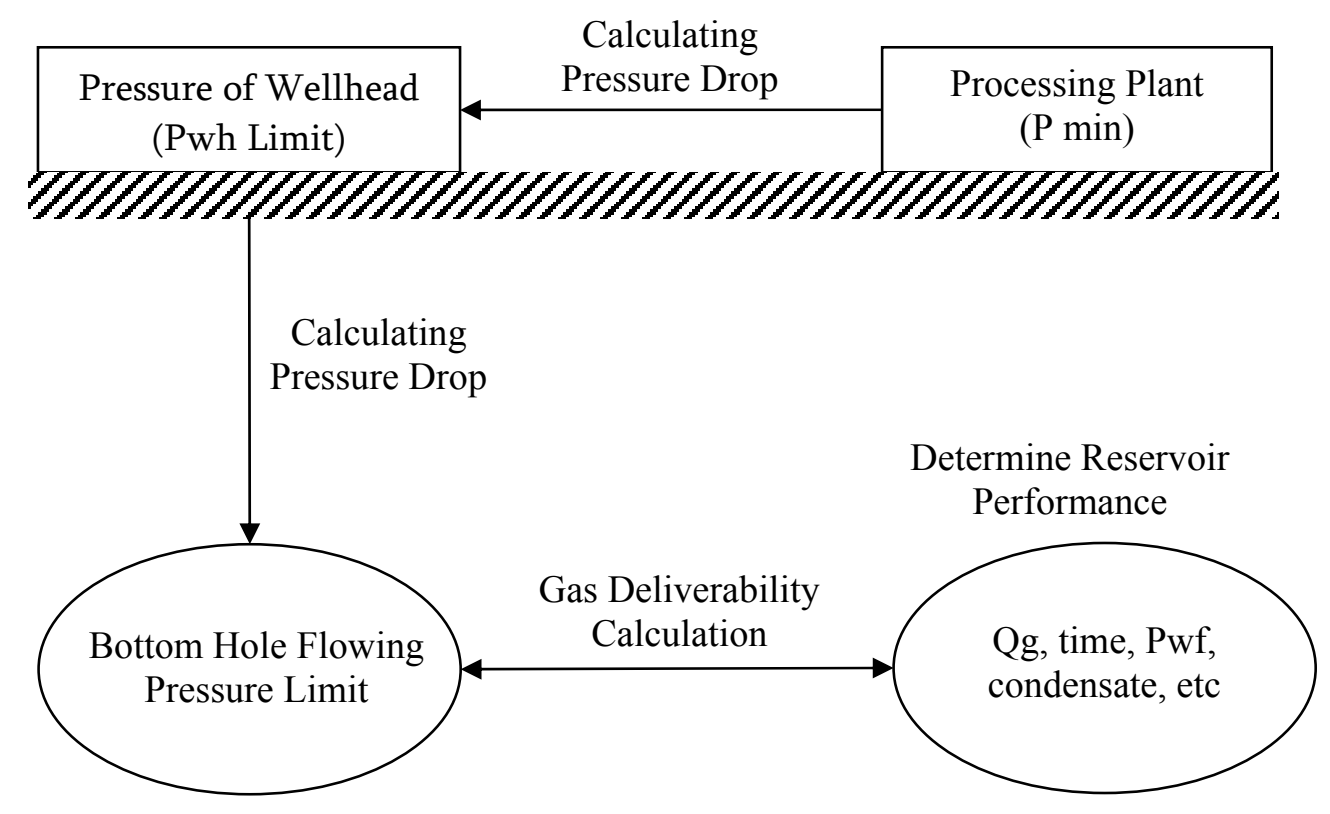

Figure 4 Flow charts represent calculation procedure in predicting gas deliverability as function of time. 


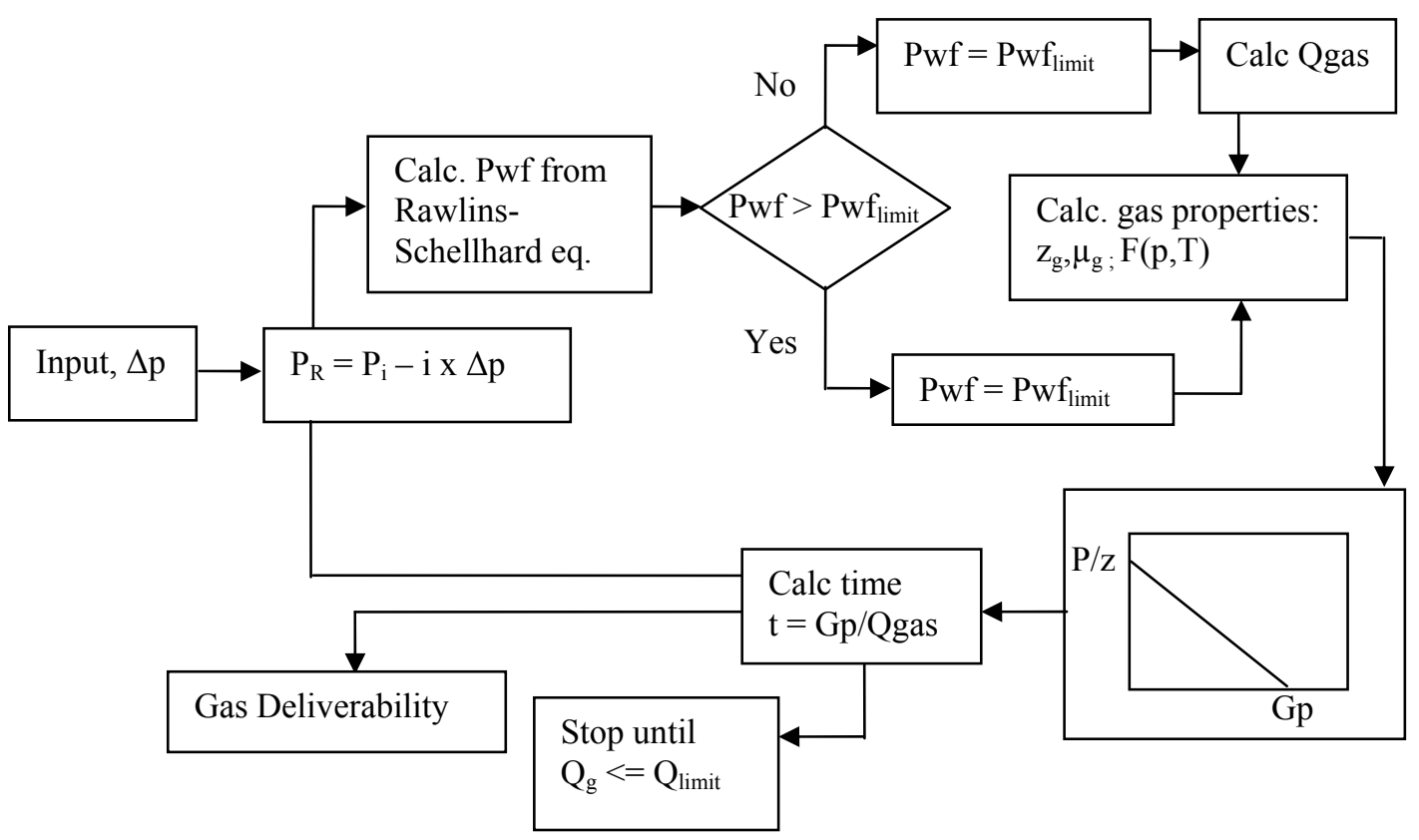

Figure 5 Flow chart of gas deliverability calculation.

\section{Sample Calculation}

Consider we have to deliver gas from single reservoir with three wells to the processing plant which can be depicted as follows

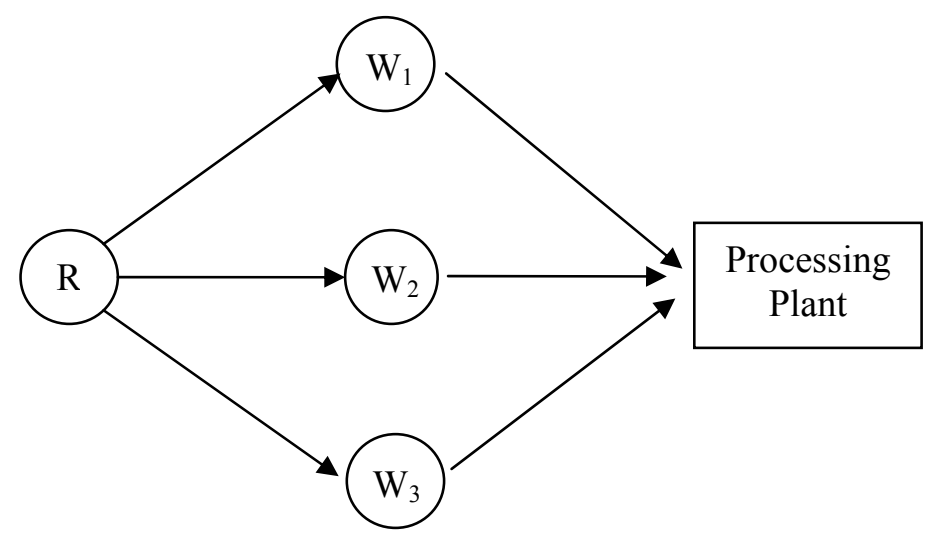

Figure 6 Illustration of the case. 
The detail data are shown below

$i$. Processing Plant:

○ Gas rate $=100$ MMscfd

$\circ$ Pressure $=300 \mathrm{psia}$

ii. Well

\begin{tabular}{|c|c|c|c|c|c|c|c|}
\hline \multirow{2}{*}{ Well } & \multirow{2}{*}{$\begin{array}{c}\mathrm{C} \\
\text { Value }\end{array}$} & \multirow{2}{*}{$\begin{array}{c}\mathrm{N} \\
\text { value }\end{array}$} & \multicolumn{5}{|c|}{ The tubing well properties } \\
\cline { 4 - 8 } & & $\begin{array}{c}\text { Depth } \\
(\mathrm{ft})\end{array}$ & $\begin{array}{c}\text { Diameter } \\
(\text { inch })\end{array}$ & $\begin{array}{c}\text { Roughness } \\
(\mathrm{inch})\end{array}$ & $\begin{array}{c}\alpha \\
(\mathrm{deg} .)\end{array}$ & $\begin{array}{c}\text { Temp. } \\
\left({ }^{\circ} \mathrm{F}\right)\end{array}$ \\
\hline Well 1 & $1.87 \times 10^{-4}$ & 0.89 & 5700 & 4.580 & $3.0 \times 10^{-4}$ & 90 & 90 \\
\hline Well 2 & $1.85 \times 10^{-4}$ & 0.90 & 7000 & 4.778 & $3.0 \times 10^{-4}$ & 90 & 90 \\
\hline Well 3 & $1.80 \times 10^{-4}$ & 0.925 & 6500 & 5.240 & $3.0 \times 10^{-4}$ & 90 & 90 \\
\hline
\end{tabular}

Table 1 Well properties.

\begin{tabular}{|c|c|c|c|c|c|}
\hline \multirow{3}{*}{ Well } & \multicolumn{5}{|c|}{ Pipelines } \\
\hline & \multicolumn{5}{|c|}{ Well - Processing plant } \\
\hline & $\begin{array}{c}\text { Length } \\
(\mathrm{ft})\end{array}$ & $\begin{array}{c}\text { Diameter } \\
\text { (inch) }\end{array}$ & $\begin{array}{l}\text { Roughness } \\
\text { (inch) }\end{array}$ & $\begin{array}{c}\alpha \\
(\mathrm{deg} .) \\
\end{array}$ & $\begin{array}{c}\text { Temp. } \\
\left({ }^{\circ} \mathrm{F}\right)\end{array}$ \\
\hline Well 1 & 2500 & 4.58 & $3.0 \times 10^{-4}$ & 0 & 90 \\
\hline Well 2 & 2800 & 4.778 & $3.0 \times 10^{-4}$ & 0 & 90 \\
\hline Well 3 & 3000 & 5.24 & $3.0 \times 10^{-4}$ & 0 & 90 \\
\hline
\end{tabular}

Table 2 Well-processing plant properties.

iii. Reservoir

$$
\begin{array}{lll}
\circ & \text { IGIP } & =300 \mathrm{Bscf} \\
\circ & \text { Pressure } & =2100 \mathrm{psia} \\
\circ & \text { Temp. } & =170^{\circ} \mathrm{F} \\
\circ & \mathrm{SG} & =0.702 \\
\circ & \mathrm{CO} 2 & =0 \% \text { mole } \\
\circ & \mathrm{H} 2 \mathrm{~S} & =0 \% \text { mole } \\
\circ & \mathrm{N} 2 & =0 \% \text { mole }
\end{array}
$$

iv. $\quad$ AOF ratio $=25 \%$

After calculating the deliverability, we have the following results.

\begin{tabular}{|c|c|c|c|}
\hline Well & $\begin{array}{c}\text { Gas rate } \\
\text { (MMscfd) }\end{array}$ & $\begin{array}{c}\text { Wellhead press. } \\
\text { (psia) }\end{array}$ & $\begin{array}{c}\text { BHP } \\
\text { (psia) }\end{array}$ \\
\hline Well 1 & 26.34 & 446.38 & 727.14 \\
\hline Well 2 & 30.36 & 469.44 & 817.37 \\
\hline Well 3 & 43.30 & 512.19 & 879.22 \\
\hline
\end{tabular}

Table 3 Calculation result. 


\begin{tabular}{|l|c|c|c|c|}
\hline Well & $\begin{array}{c}\text { Plateau } \\
\text { Time } \\
\text { (year) }\end{array}$ & $\begin{array}{c}\text { Prod. Time } \\
\text { (year) }\end{array}$ & $\begin{array}{c}\text { Cumulative Gas } \\
\text { @ Plateau } \\
\text { (BSCF) }\end{array}$ & $\begin{array}{c}\text { Cumulative Gas } \\
\text { @ Prod. Time } \\
\text { (BSCF) }\end{array}$ \\
\hline Well 1 & 4.57 & 18.34 & 43.67 & 72.13 \\
\hline Well 2 & 4.19 & 7.53 & 46.44 & 58.77 \\
\hline Well 3 & 3.91 & 5.92 & 61.83 & 74.16 \\
\hline Total Result & 3.91 & 5.92 & 142.78 & 205.06 \\
\hline
\end{tabular}

Table 4 Gas deliverability result

To get detailed results, see figures 7,8 , and 9 .

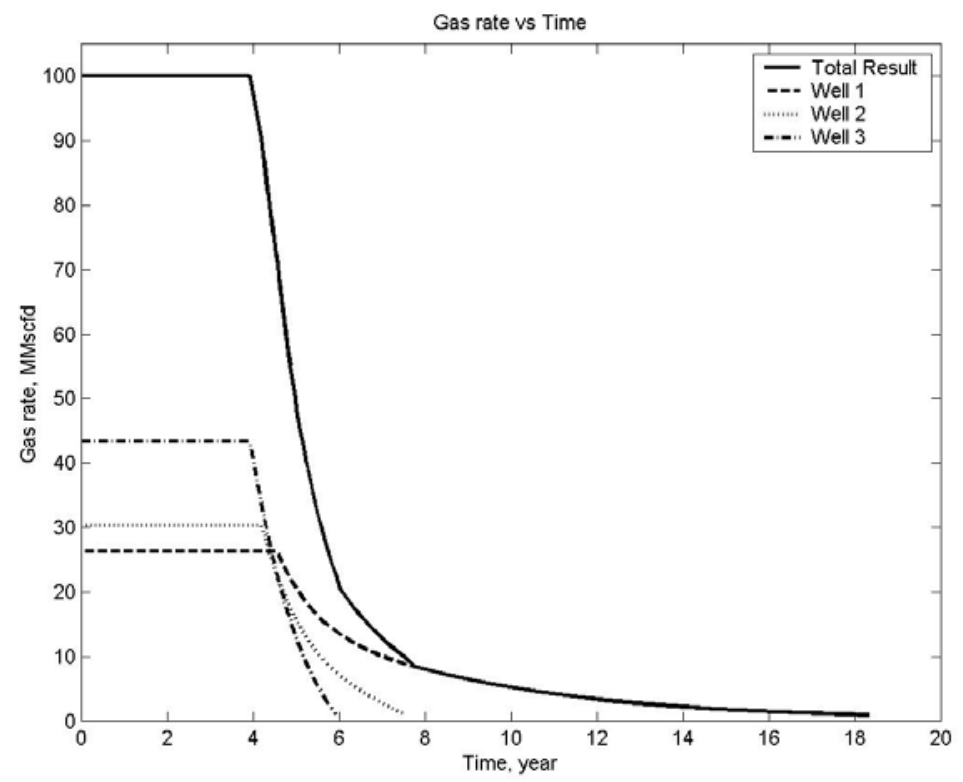

Figure 7 Profile of gas rate versus time.

\section{$7 \quad$ Numerical Analysis and Further Discussion}

Here, we determine gas rate allocation that can be taken from each well by a weighted initial AOF value. Within the computation, the initial AOF value of each well is changed due to the change of reservoir pressure.

After calculating the rate, we must check whether gas from all wells satisfies the customer needs or not. If it doesn't, then we should establish a new well. Otherwise, the demand cannot be fulfilled. 


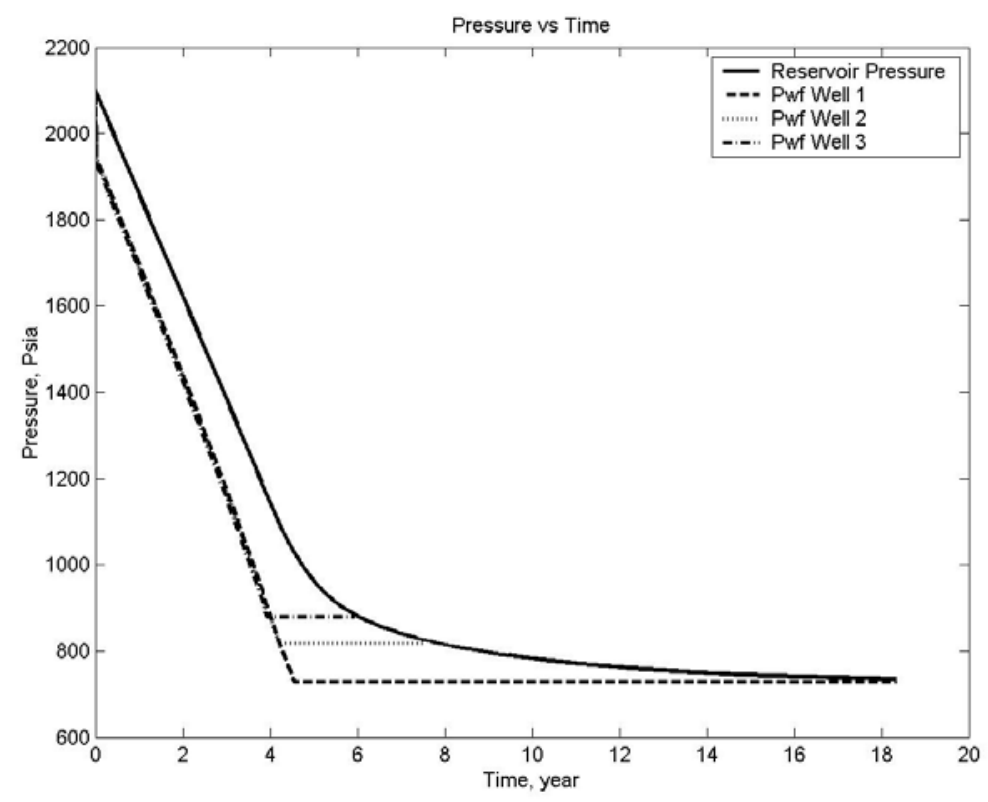

Figure 8 Profile of pressure versus time.

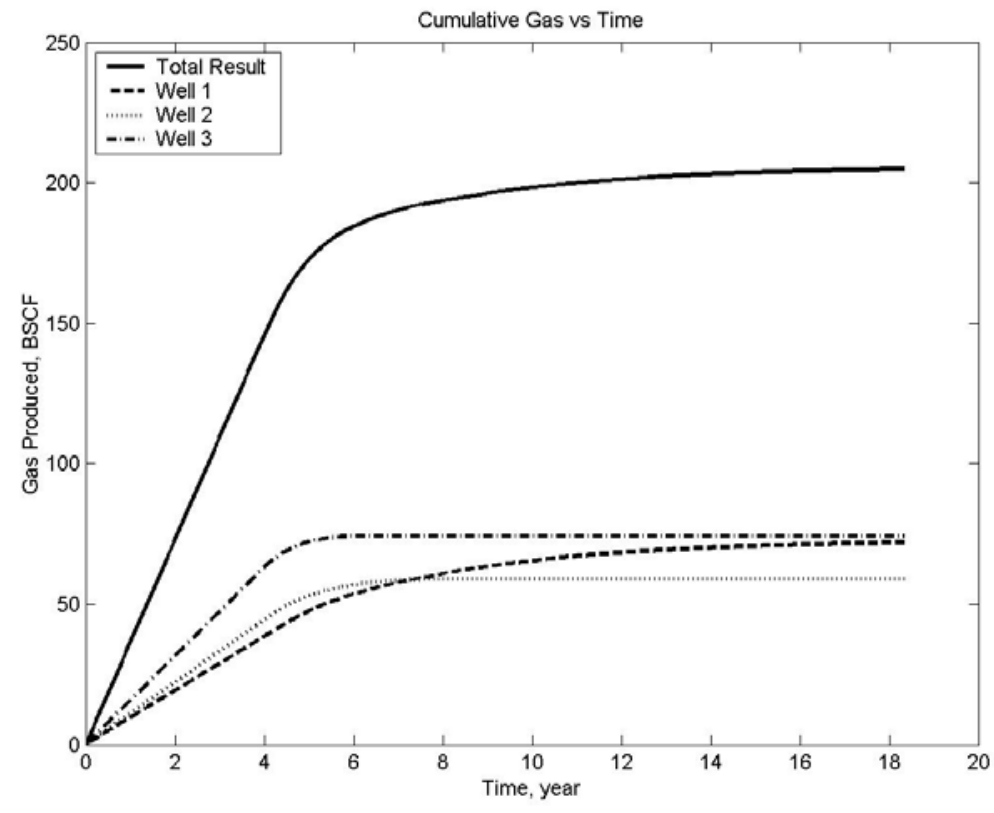

Figure 9 Profile of cumulative gas versus time. 
In short, it can be said that we divide the calculation into three stages. First, we should estimate gas rate that can be produced from each well and then evaluate whether it can satisfy the demand. Secondly, we should predict pressure drop for each well so that the entire bottom holes pressures can be found. And finally, we calculate the deliverability for all wells simultaneously. However, we must be careful because there are some properties of wells that could be different one another and would always change for every different time.

In the sample case above, it can be seen that if we have multi-wells with different properties, then we will have different profiles for each well (i.e. gas rate, plateau time, producing time, gas cumulative, etc).

We should also point out that in estimating pressure drop, Runge-Kutta method is used to solve the Tian-Adewumi correlation. This method is a well-known method to solve ordinary differential equation problem because of its accuracy. By this method, the best approach solution of the problem can be obtained.

\section{$8 \quad$ Summaries}

1. The gas deliverability model in this study is basically developed based on the material balance method in which vertical wells with different properties can be modeled and implemented for predicting gas deliverability of a gas field.

2. For better industry application, future development of this model will include multiple reservoir system, complex well completions, and various surface separator conditions

\section{Acknowledgement}

The authors would like to thank the Research Consortium OPPINET for funding the research.

\section{Nomenclature}

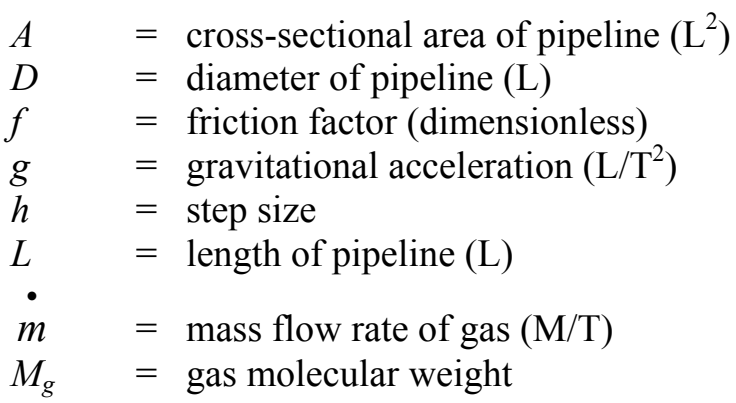




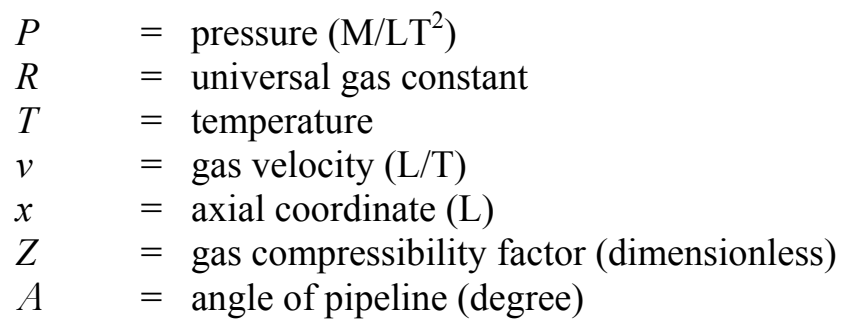

\section{References}

1. Fevang, O. \& Whitson C. H., Modeling Gas Condensate Well Deliverability, Proc. Of 1995 SPE Annual Technical Conference (Oct. 22 $-25,1995)$ p. 103-118.

2. Mott, R., Calculating Well Deliverability in Gas Condensate Reservoirs, EAGE $-10^{\text {th }}$ European Symposium on Improved Oil Recovery, Brighton - UK, August 18 - 20 (1999).

3. Tian, Shifeng \& Adewumi, M. A., Development of Analytical Design Equation for Gas Pipelines, Proc. Of 1992 SPE Annual Technical Conference, (Oct. 4 - 7, 1992) p. 989-256.

4. Ikoku, C. U., Natural Gas Production Engineering, John Wiley \& Sons Inc., New York (1984).

5. Zhou, Junyang \& Adewumi, M. A., The Development and Testing of a New Flow Equation, Proceeding of PSIG Meeting, Houston, TX (1995).

6. Hoffman, J. D., Numerical Methods for Engineers and Scientists, McGraw-Hill International Editions (1993).

7. Ahmed, T., Hydrocarbon Phase Behavior, Gulf Publishing Company, Houston, Texas (1989). 